\title{
Infectious Complications of Ventricular Assist Device Use in Children in the US: Data from the Pediatric Interagency Registry for Mechanical Circulatory Support (Pedimacs)
}

\author{
Scott R. Auerbach, MD ${ }^{1}$, Marc E. Richmond, MD, MS $^{2}$, Kurt R. Schumacher, MD, MS $^{3}$, Dalia \\ Lopez-Colon, $\mathrm{PhD}^{4}$, Max B. Mitchell, MD ${ }^{5}$, M. W. Turrentine, $\mathrm{MD}^{6}$, Ryan S. Cantor, MSPH${ }^{7}$, \\ Robert A. Niebler, MD $^{8}$, and Pirooz Eghtesady, MD, PhD $^{9}$ \\ ${ }^{1}$ Pediatrics, Division of Cardiology, University of Colorado Anschutz Medical Campus and \\ Children's Hospital Colorado, Aurora, CO \\ ${ }^{2}$ Division of Pediatric Cardiology, Columbia University, New York, NY \\ ${ }^{3}$ Pediatrics, Cardiology, University of Michigan, Ann Arbor, MI \\ ${ }^{4}$ Pediatrics, Congenital Heart Center, University of Florida, Gainesville, FL \\ ${ }^{5}$ Pediatric Cardiothoracic Surgery, University of Colorado Anschutz Medical Campus and \\ Children's Hospital Colorado, Aurora, CO \\ ${ }^{6}$ Department of Surgery, Division of Thoracic and Cardiovascular Surgery, Indiana University \\ School of Medicine, Indianapolis, IN \\ ${ }^{7}$ Kirklin Institute for Research in Surgical Outcomes, The University of Alabama at Birmingham, \\ $\mathrm{AL}$ \\ ${ }^{8}$ Pediatrics, Medical College of Wisconsin, Milwaukee, WI \\ ${ }^{9}$ Surgery-Cardiothoracic, Washington University School of Medicine, St. Louis, MO
}

\begin{abstract}
Background-Infections are frequent in pediatric ventricular assist device (VAD) patients. We aimed to describe infections in durable VAD patients reported to Pedimacs.

Methods-Durable VAD data from the Pedimacs registry (9/19/2012-12/31/2015) were analyzed. Infections were described with standard descriptive statistics, Kaplan-Meier analysis, and competing outcomes analysis.
\end{abstract}

Results-There were 248 implants in 222 patients with a mean age and a median follow-up of $11 \pm 6.4$ years and 2.4 patient-months ( $<1$ day-2.6 year), respectively. Device types were pulsatile

Correspondence/Reprint Requests: Scott Auerbach, M.D, Associate Professor of Pediatrics, Medical Director, VAD Program, University of Colorado Anschutz Medical Campus, Children's Hospital Colorado Heart Institute, 13123 East $16^{\text {th }}$ Avenue, Aurora, $\mathrm{CO} 80045$.

This work was presented at the International Society for Heart and Lung Transplantation Conference on April 28th, 2016.

Publisher's Disclaimer: This is a PDF file of an unedited manuscript that has been accepted for publication. As a service to our customers we are providing this early version of the manuscript. The manuscript will undergo copyediting, typesetting, and review of the resulting proof before it is published in its final citable form. Please note that during the production process errors may be discovered which could affect the content, and all legal disclaimers that apply to the journal pertain. 
flow (PF) in 91 (41\%) patients and continuous flow (CF) in 131 (59\%) patients. PF patients were younger ( $4 \pm 4$ vs $14 \pm 4 \mathrm{yr} ; \mathrm{p}<0.0001)$ and were more likely to have congenital heart disease $(25 \%$ vs $12 \%$; $\mathrm{p}=0.03$ ), prior surgery ( $53 \%$ vs $26 \%$; $\mathrm{p}<0.0001)$, and prior ECMO ( $24 \%$ vs $7 \%$; $\mathrm{p}=0.0003)$. Infection accounted for $17 \%(96 / 564)$ of reported adverse events (AE). A non-device infection was most common (51\%), followed by sepsis (24\%), external pump component infection (20\%), and internal pump component infection (5\%). Most infections were bacterial (73\%) and required IV therapy only (77\%). The risk of infection in the constant phase was higher in patients with a history of prior infection and in patients with a history of a non-infectious major AE. Survival was lower following infection only in CF patients $(\mathrm{p}=0.008)$.

Conclusions-Infection was the most common AE after pediatric VAD implantation. Nondevice infections were most common. The best predictor of a future infection was a past infection. CF patients have higher risk of death after an infection.

\section{Keywords}

ventricular assist device; adverse events; continuous-flow device; Pulsatile-flow device; infection

\section{Introduction}

The use of ventricular assist devices (VAD) in children has increased dramatically over the last decade in both children and adults, with a marked improvement in survival to transplantation ${ }^{1-5}$. However, adverse events (AE) remain a common problem following device placement ${ }^{5-7}$. Our ability to minimize AE depends on a thorough understanding of the event rates, event severity, risk factors for $\mathrm{AE}$, and associations between various $\mathrm{AE}$. Infectious complications are one of the most common AE related to pediatric VAD use. Adult studies have shown the infection rate to be 8.2 per 100 pt-months ${ }^{5}$. Retrospective and prospective studies of pediatric VAD use have reported that 40-63\% of patients develop an infection while on VAD support ${ }^{8-11}$. Retrospective studies of pediatric VAD use have shown rates of infection of 1.5-5.4 infections per 100 VAD days (46-164 infections per 100 pt-months) for the Berlin Heart EXCOR and have shown thromboembolic events to be associated with infection ${ }^{8,11}$. A study comparing outcomes and AE of continuous flow VADs in children and adults reported infection rates of 1.12 and 0.97 infections per pt-year (9.3 and 8.1 infections per $100 \mathrm{pt}-\mathrm{months}$ ) in children and adults, respectively, and nondevice infections were most common ${ }^{12}$. In a recent analysis of the Pedimacs registry, there were $263 \mathrm{AE}$ in 135 patients, of which $19.8 \%$ were due to infection. The early infection rate (within 3 months post-implant) was 15.0 events per 100 pt-months and the late infection rate (after 3 months) was 2.3 events per 100 pt-months ${ }^{10}$. However, details about the types of infection were not reported and further information about infectious complications is needed to help guide management decisions in pediatric patients. A detailed analysis of the Pedimacs registry will provide beneficial data on the types of and risks for infectious complications observed in children. The objective of this manuscript is to expand on the first contemporary, national-level description of the adverse events associated with the full spectrum of pediatric VAD use in the United States by providing a detailed description and analysis of infectious adverse events (IAE). 


\section{Methods}

The Interagency Registry for Mechanically Assisted Circulatory Support (Intermacs) is a National Institutes of Health funded, U.S. national registry of patients supported by FDAapproved VAD, which now contains data on $>15,000$ patients ${ }^{5}$. Pedimacs, the pediatric component of Intermacs, began enrolling pediatric patients supported with VAD on September1, 2012 and at the time of this analysis included data from 41 centers. The Pedimacs registry has been previously described in detail ${ }^{13}$. Pedimacs enrolled 275 prospective patients implanted between September 19, 2012 and December 31, 2015. For this study, we included patients receiving at least one long-term device and excluded patients that received either a temporary support device or a total artificial heart.

$\mathrm{AE}$ in Pedimacs are categorized using a pre-specified dictionary of adverse events that is provided to each participating site. The definitions were derived by expert consensus, working in large part from the definitions already employed in Intermacs, and altering them as necessary to be appropriate for pediatric patients. Pedimacs AE have been previously described and entire list of AE used in Pedimacs and their definitions can be reviewed on the Pedimacs website (https://www.uab.edu/medicine/intermacs/appendices-5-ped/appendix-aadverse-event-definitions) $)^{14}$. Pedimacs major AE (MAE) for this analysis are defined as major infection, device malfunction, major bleeding, and neurologic dysfunction. A major infection or infectious $\mathrm{AE}$ is defined as "a clinical infection accompanied by pain, fever, drainage and/or leukocytosis that is treated by anti-microbial agents (non-prophylactic). A positive culture from the infected site or organ should be present unless strong clinical evidence indicates the need for treatment despite negative cultures." Definitions of infectious AE locations are as follows:

1. Localized Non-Device Infection: Infection localized to any organ system or region without evidence of systemic involvement (see sepsis definition), ascertained by standard clinical methods and either associated with evidence of bacterial, viral, fungal or protozoal infection, and/or requiring empirical treatment.

2. External Pump Component: A positive culture from the skin and/or tissue surrounding the drive line or from the tissue surrounding the external housing of a pump implanted within the body, coupled with the need to treat with antimicrobial therapy, when there is clinical evidence of infection such as pain, fever, drainage, or leukocytosis. For the purposes of this analysis, an infection location designated as mediastinum was considered an external pump component infection rather than localized non-device infection. This location refers to an infection of the device that is not in contact with the blood-device interface.

3. Internal Pump Component, Inflow or Outflow Tract Infection: Infection of blood-contacting surfaces of the LVAD documented by positive site culture.

4. Sepsis: Evidence of systemic involvement by infection, manifested by positive blood cultures and/or hypotension. 
To determine the effect of prior major $\mathrm{AE}$ on subsequent $\mathrm{AE}$ we have segmented the patient follow-up times into intervals at each major $\mathrm{AE}$ and devised two covariates defined for each segment.

1. History of Prior Infectious AE. A patient's history of infectious AE was determined at the time of infection event. For example, the first infection event would be one without any other prior infection event. All subsequent infection events would be classified as having a history of infection.

2. History of Non-Infection Major AE. A patient's history of at least one major non-infection adverse event (bleeding, device malfunction, neurological dysfunction) was determined for each time segment.

\section{Statistical Analysis}

Patient characteristics were evaluated using descriptive statistics. Continuous variables were described as means with standard deviations (and analyzed using t-tests) or median with interquartile range [IQR] (and analyzed with the Mann-Whitney U test), as appropriate. Categorical variables were described as counts and percentages and compared using chisquared or Fisher's exact test. Infectious AE were categorized based on location: localized non-device (pulmonary, urinary tract, peripheral wound, gastrointestinal, unknown, and other); external pump component (driveline, exit cannula, mediastinum); internal pump component (pump interior, pump pocket); or sepsis (positive blood cultures, line sepsis). The timing of the infectious AE was categorized as early if it occurred within 3 months after an implant and late if it occurred more than 3 months after an implant, consistent with other reporting in both Intermacs and Pedimacs. Multiple events were allowed for patients. Early and late infectious AE rates were calculated overall and for each infection category. Time to first infectious AE was determined using Kaplan Meier survival comparison between groups using the log rank test. Competing outcomes methodology was used to calculate the timerelated probability of patients having an infectious $\mathrm{AE}$, being alive and on support and free of infectious AE, receiving a heart transplant without infection, or recovery free from infectious AE. To determine the effect of infectious AE on subsequent survival, Kaplan Meier estimates for survival on a device were calculated for patients without or prior to an infectious AE (censoring at transplant, recovery, or first infection) and compared with estimates based on survival on a device after the first infectious $\mathrm{AE}^{15}$. Associations between infectious $\mathrm{AE}$ and major $\mathrm{AE}$ were determined with multi-phase, parametric hazard modeling using time-varying covariates for this history of MAE or the history of IAE. This parametric model included an early decreasing phase of hazard in addition of a constant hazard. The model was adjusted also for flow type of the device (PF or CF). There were 2 major AE on the day of device implant that were not used for analysis of associations between infectious $\mathrm{AE}$ and major AE. Pedimacs defines major AE as bleeding, infection, neurologic event, and device malfunction. All analyses were conducted using SAS 9.4. 


\section{Results}

\section{Patient Enrollment and Characteristics}

There were 275 patients enrolled in Pedimacs during the study period, of whom 222 received a durable device and were included in this cohort. There were 46 patients on temporary support and 7 on total artificial heart support that were excluded. There were 131 patients (59\%) that received a continuous flow device (CF) and $91(41 \%)$ that received a pulsatile flow device (PF). The CF group consisted of 122 left ventricular assist devices (LVAD), 7 biventricular assist devices (BiVAD), and 2 right ventricular assist devices. The PF group consisted of $65 \mathrm{LVAD}, 24 \mathrm{BiVAD}$, and $2 \mathrm{RVAD}$. The median time on a device was 2.6 patient-months (range $<1$ day -2.6 years) with no difference in median time on device between CF and PF groups (2.5 months, IQR [1.2-5.6] vs. 1.9 months, IQR [0.8-5.2], respectively; $\mathrm{p}=0.16$ ). This represented 73.4 patients-years with a durable device in place.

Clinical characteristics are compared between patients with PF and CF devices in Table 1. There were significant differences between $\mathrm{PF}$ and $\mathrm{CF}$ patients. PF patients were significantly younger $(\mathrm{p}<0.001)$, more likely to have a diagnosis of congenital heart disease $(\mathrm{P}=0.029)$, have a smaller body surface area $(\mathrm{p}<0.001)$, have a history of extracorporeal membrane oxygenation (ECMO) prior to implantation $(\mathrm{P}=0.0003)$, and have a history of prior cardiac surgery $(\mathrm{p}<0.0001)$. Differences in laboratory data prior to implantation included the PF group having higher brain natriuretic and pro-brain natriuretic peptide levels $(\mathrm{P}=0.0003$ and $\mathrm{p}=0.024$, respectively) and higher white blood cell and lymphocyte counts ( $\mathrm{p}=0.0007$ and $\mathrm{p}=0.043$, respectively. Variables for which there was no difference between groups included blood urea nitrogen, previous mechanical circulatory support device, aspartate or alanine aminotransferases, albumin, pre-albumin, hemoglobin, platelet count, international normalized ratio, uric acid, eGFR, total bilirubin, and malnutrition/cachexia.

Implant Characteristics were compared between PF and CF patients, as shown in Table 2. There were significant differences between PF and CF patients. PF patients were more likely to be classified as patient profile 1 rather than profiles $2-4(\mathrm{P}=0.0125)$, to have a device strategy of bridge to transplant vs. bridge to decision ( $\mathrm{p}=0.0026$ ), and to have BiVAD support vs. LVAD support $(\mathrm{p}<0.0001)$.

\section{Patient Survival}

As of December 31, 2015, there were 33 (14.9\%) who were alive on a device, 143 (64.4\%) who were transplanted, $34(15.3 \%)$ who had died, and $3(1.4 \%)$ who had recovered. The median time on a device was 2.4 patient-months (range $<1$ day-2.7 years). This represented 73.4 patients-years with a durable device in place. There was no difference in time on device between PF and CF groups ( $\mathrm{p}=0.16$ ). Competing outcomes analysis can be found in the online supplement (Supplemental Figures 1-3). The proportions of patients transplanted, alive on device, dead, and explanted at 6 months post-implant for PF device patients were $54.5 \%, 21.6 \%, 23.9 \%$, and $0 \%$ and for $\mathrm{CF}$ device patients were $64.3 \%, 28 \%, 7.7 \%$, and $0 \%$. 


\section{Rates of Infectious Adverse Events}

There were 59 patients who had at least one infectious AE (26.6\%). There was a total of 95 infectious AE during the study period. Infectious AE represented $17 \%$ of all $\mathrm{AE}$, making it the most common of all $\mathrm{AE}$ for this cohort. There were 34 patients (15.3\%) with one infectious AE, $18(8.1 \%)$ with 2 infectious AE, and $6(3.2 \%)$ with 33 infectious AE. The 2 device types had a similar proportion of $\mathrm{AE}$ that were infectious, at $17 \%$ and $16 \%$ of $\mathrm{AE}$ in the $\mathrm{PF}$ and $\mathrm{CF}$ groups, respectively $(\mathrm{p}=0.9$ ). Following infectious $\mathrm{AE}$, the next most frequent $\mathrm{AE}$ were device malfunction (14\%) and major bleeding (13\%). An infectious AE directly contributed to death in 5 patients (5\%), including 3 (7\%) PF patients and $2(3 \%) \mathrm{CF}$ patients.

Infectious AE Rates by timing and location of infectious AE are shown in Table 3. Early infectious $\mathrm{AE}$ were more common than late infectious $\mathrm{AE}$ for all patients (14.5 vs 7.2 infectious AE per 100 patient-months), for PF patients (18.0 vs 10.2 infectious AE per 100 patient-months), and for CF patients (12.3 vs 6.3 infectious AE per 100 patient-months). The most common infectious AE by location was localized non-device $(49,51 \%)$ followed by sepsis $(23,24 \%)$, external pump component $(19,20 \%)$, and internal pump component (5, $5 \%)$. While rates of overall early infectious AE were not statistically different between device types ( 18.0 vs 12.3 per 100 patient-months $(\mathrm{p}=0.12)$, there was a significantly higher rate of early sepsis in PF vs CF patients (6.4 vs 2.2 per 100 patient-months, respectively; $(\mathrm{p}=0.03)$. There were 12 infectious AE that occurred in the outpatient setting, all of which occurred in the $\mathrm{CF}$ group. Types of infectious AE seen in the outpatient setting included sepsis $(\mathrm{N}=4)$, drive line site infection $(\mathrm{N}=4)$, urinary tract infection $(\mathrm{N}=1)$, pneumonia $(\mathrm{N}=1)$, acute otitis media $(\mathrm{N}=1)$, and cellulitis $(\mathrm{N}=1)$.

\section{Characteristics of Infectious Adverse Events}

Table 4 shows the type of infectious agent responsible for infectious $\mathrm{AE}$ and the management of infectious AE. The type responsible for the infectious AE included bacterial (70 infectious $\mathrm{AE}, 73 \%$ ) fungal (12 infectious $\mathrm{AE}, 12 \%$ ), viral (8 infectious $\mathrm{AE}, 8 \%$ ), and unknown (5 infectious AE, 5\%). Management of infectious AE included intravenous drug therapy only (74 infectious $\mathrm{AE}, 77 \%$ ), oral drug therapy (11 infectious $\mathrm{AE}, 11 \%)$, surgical and drug therapy ( 8 infectious AE, $8 \%$ ), and unknown (2 infectious AE, $2 \%$ ).

\section{Freedom from Infection}

Competing outcomes analyses including time to a first infectious $\mathrm{AE}$ by device type are shown in figure 1A and 1B. At 6 months post-implant, a higher percentage of PF vs $\mathrm{CF}$ patients had experienced a first infectious AE $29.7 \%$ vs $21.2 \%$, respectively) and a lower percentage of $\mathrm{PF}$ vs $\mathrm{CF}$ patients underwent transplantation without an infectious $\mathrm{AE}$ (42.7\% vs $56.0 \%$, respectively).

Kaplan Meier survival analysis comparing freedom from infectious AE in all patients stratified by device type is shown in figure 2 . While there was not a statistically significant difference in freedom from an infectious AE, the curves separate 2 months after implantation. Hazard modeling of the early and late phase show that the risk of infection in the early phase is not significantly different between device types (HR 0.7, 95\% CI [0.13.2]). However, the risk of infectious $\mathrm{AE}$ in the late phase is significantly higher in the $\mathrm{PF}$ 
group (HR 2.6, 95\% CI [1.2-6.0]). Freedom from first infectious AE stratified by patient profile was not associated with a lower freedom from infectious $\mathrm{AE}$ when comparing profile 1 to profiles $2-4$ in either the $\mathrm{PF}$ or $\mathrm{CF}$ groups ( $\mathrm{p}=0.43$ and $\mathrm{p}=0.73$, respectively).

\section{Survival on Device after an Infection}

Patient survival following a first infectious AE was significantly worse compared to survival in those without an infectious $\mathrm{AE}(\mathrm{p}=0.042$, Figure $3 \mathrm{~A})$. When this was evaluated by device type, there was not a significant difference in survival between patients with and without a prior infection in the pulsatile group (Figure $3 \mathrm{~B}, \mathrm{p}=0.77$ ). However, survival was significantly worse in patients with $\mathrm{CF}$ devices following a first infection (Figure 3C, $\mathrm{p}=0.0076)$.

\section{Associations Between Infectious AE and Major AE}

Table 5 shows the risk of infectious AE following a prior infectious AE and following a noninfectious MAE (after controlling for device type). A prior infectious AE was associated with a subsequent infectious AE only during the late phase (HR 1.9, 95\% CI [1.0-3.4]; $\mathrm{p}=0.04)$. A history of a non-infectious MAE was also associated with a subsequent infectious AE (HR 1.9, 95\% CI [1.0-3.8]; $\mathrm{p}=0.05$ ).

\section{Discussion}

The ability of VAD use to improve survival to transplant in children has been known for decades ${ }^{2}, 16$. More recently, the development of Pedimacs has allowed for the study of VAD specific outcomes in a multicenter fashion. The initial Pedimacs reports showed excellent outcomes related to $\mathrm{VAD}$ use, but showed a significant number of $\mathrm{AE}^{17}{ }^{18}$. A subsequent, more detailed Pedimacs analysis of AE related to VAD use, showed that infection is one of the most frequent $\mathrm{AE}$, along with device malfunction, bleeding and neurologic dysfunction. Due to the high rates of infectious $\mathrm{AE}$ in these previous reports, this analysis was proposed to obtain a better understanding of infectious $\mathrm{AE}$ in children on VAD support.

This study demonstrated that infection is the most common AE following VAD placement, which is consistent with single center reports and earlier Pedimacs studies ${ }^{14}$ 19-21. This differs only slightly from adult Intermacs data, which showed that bleeding was the most common $\mathrm{AE}$, while infectious $\mathrm{AE}$ were a very close second ${ }^{5}$. We found that infectious $\mathrm{AE}$ occur more frequently in the early period after VAD implant, which is not surprising, as single center studies of VAD use in children have shown that the AE rate is highest in the first week after implantation ${ }^{21}$. Furthermore, adult data from Intermacs showed the peak hazard of infectious AE occurred in the early period after implant ${ }^{5}$. The early period after implantation is a time during which the VAD patient is more likely to be exposed to intensive care and have indwelling lines and catheters, while also being in a state of suboptimal nutrition. De-intensification of patient care decreases the risk of infection and has usually been optimized by 3 months post-transplant. While the calculated rates of infectious AE were slightly higher in PF patients in both the early and late period compared to the CF patients, we did not find a difference in freedom from infectious AE between the groups in the early phase. This was somewhat surprising given that there was a higher 
proportion of PF patients that were Intermacs Profile I and that required biventricular support. Given that there was lower survival in the pulsatile group, it is possible that patients most likely to develop an infectious AE died prior to the onset of an infectious AE. With that in mind, it is not surprising that the risk of infection was higher in the pulsatile group in the late phase after VAD placement. Pedimacs PF patients are required to remain in the hospital for the duration of their VAD course and are exposed to the infectious risk associated with long term inpatient stays. The PF patients were younger, more likely to have been on BIVAD support, more likely to have been Intermacs Patient Profile I, and more likely to have undergone previous cardiac surgery, all of which make recovery, mobilization and rehabilitation more difficult and may explain the higher incidence of late infectious AE.

Another notable finding is that the vast majority of infectious AE are not of the device itself, but are located elsewhere (pneumonia, line sepsis, urinary tract infection, gastroenteritis, etc.), These infections are a reflection of the chronic disease state of the patient. This finding is similar to single center pediatric studies showing that most infectious AE are caused by sepsis or localized non-device infection and Intermacs data showing that adult patients were most likely to develop pneumonia and sepsis before developing a percutaneous site infection ${ }^{21,22}$.

Approximately $2 / 3$ of the infectious $\mathrm{AE}$ were able to be treated with medical therapy alone and only $3 \%$ required surgical intervention. The vast majority of the infections were bacterial in nature. The types of organisms causing infectious $\mathrm{AE}$ between groups was similar with the exception of a slightly higher proportion of fungal infections in the continuous flow group. The reason for this is unclear, but these infections were mostly nondevice related. There were 9 total fungal infectious $\mathrm{AE}$ in the continuous flow group with the following sources: pulmonary $(\mathrm{N}=5)$, urinary tract $(\mathrm{N}=1)$, bloodstream $(\mathrm{N}=1)$, cellulitis $(\mathrm{N}=1)$, and mediastinum $(\mathrm{N}=1)$. None of these fungal infections required surgical intervention. Surgical intervention to treat an infectious AE was only required in 8 infectious $\mathrm{AE}$ (7 patients). While not statistically significant due to the small $\mathrm{N}$, there was a higher proportion of infectious $\mathrm{AE}$ were treated with surgery in the pulsatile group (14\% vs 3\%; $\mathrm{p}=0.07)$. These pump related infections may be due to a relatively larger device -patient interface in the PF patients.

Overall, there was no difference in survival following a $1^{\text {st }}$ infectious AE. However, when we separated patients by device type, survival was lower following a $1^{\text {st }}$ infectious $\mathrm{AE}$ in continuous flow device patients compared to those without an infectious AE (Figure 3C). The reason for this is unclear but the finding mirrors Intermacs data showing that patients on CF devices with a history of a percutaneous site infection had lower survival after VAD implantation $^{22}$. In our analysis, there were 7 deaths following infectious AE and only 2 of those were felt to contribute to their death. While infection can certainly directly result in death, it may also be a surrogate for other complications or risk factors for death following device placement. The lack of difference in survival after a first infectious AE in the pulsatile group is likely due to the lower overall survival rate, resulting in lower potential to detect a difference is survival after infectious AE. Previous reports and Pedimacs data have shown that the most common causes of death in this group are not infectious, but rather due to neurologic injury, respiratory failure, bleeding, and multi-organ system failure ${ }^{23}$. 
We also found associations between MAE (infectious and non-infectious) and a subsequent infectious AE. After controlling for device type, a MAE was associated with a subsequent infectious AE in only in the late phase. The findings that both infectious and non-infectious MAE were associated with future infectious $\mathrm{AE}$ are not surprising as the conditions and risk factors that lead to the infectious AE often persist for months after VAD implantation.

This study has its limitations. Foremost, the analysis is limited by small numbers and, therefore, it is mostly descriptive in nature. For example, we were unable to determine whether BiVAD use resulted in a higher risk of infection and we were unable to properly model pre-transplant risk factors for infection due to lack of power. This also limits the inference that can be drawn from the multivariate modeling, as only strong associations may be observed. Comparisons between pulsatile and continuous flow devices should be considered descriptive because of the significant differences in pre-implant characteristics between the groups. This analysis has been performed early in the Pedimacs experience and overtime a more robust database will allow us to power some of the analyses that we were unable to do at this time. Finally, the database only provides a category of infection (i.e. bacterial, viral, fungal, etc.) and does not provide data on specific organisms causing infection.

In summary, this is the first detailed analysis of infectious $\mathrm{AE}$ in pediatric VAD recipients using the Pedimacs registry. Infectious AE are the most common AE seen in the population and most often occur in the early period post-implant. Most infections are not device related and can be treated with medical therapy. A previous MAE is predictive of future infectious $\mathrm{AE}$ and patients with $\mathrm{CF}$ devices who develop an infectious $\mathrm{AE}$ are at higher risk of death while on VAD support.

\section{Acknowledgments}

We would like to thank the Pedimacs/Intermacs data coordinating center for their assistance in the data analysis and the Pedimacs Data Access, Analysis, and Publications Committee and the Intermacs Executive Committee for their review of the manuscript. The authors have no disclosures.

\section{References}

1. Mansfield RT, Lin KY, Zaoutis T, Mott AR, Mohamad Z, Luan X, Kaufman BD, Ravishankar C, Gaynor JW, Shaddy RE, Rossano JW. The Use of Pediatric Ventricular Assist Devices in Children's Hospitals From 2000 to 2010: Morbidity, Mortality, and Hospital Charges. Pediatric critical care medicine : a journal of the Society of Critical Care Medicine and the World Federation of Pediatric Intensive and Critical Care Societies. 2015

2. Blume ED, Naftel DC, Bastardi HJ, Duncan BW, Kirklin JK, Webber SA. Outcomes of children bridged to heart transplantation with ventricular assist devices: a multi-institutional study. Circulation. 2006; 113:2313-9. [PubMed: 16702487]

3. Morales DL, Almond CS, Jaquiss RD, Rosenthal DN, Naftel DC, Massicotte MP, Humpl T, Turrentine MW, Tweddell JS, Cohen GA, Kroslowitz R, Devaney EJ, Canter CE, Fynn-Thompson F, Reinhartz O, Imamura M, Ghanayem NS, Buchholz H, Furness S, Mazor R, Gandhi SK, Fraser CD Jr. Bridging children of all sizes to cardiac transplantation: the initial multicenter North American experience with the Berlin Heart EXCOR ventricular assist device. The Journal of heart and lung transplantation : the official publication of the International Society for Heart Transplantation. 2011; 30:1-8. 
4. Zafar F, Castleberry C, Khan MS, Mehta V, Bryant R 3rd, Lorts A, Wilmot I, Jefferies JL, Chin C, Morales DL. Pediatric heart transplant waiting list mortality in the era of ventricular assist devices. J Heart Lung Transplant. 2015; 34:82-8. [PubMed: 25447574]

5. Kirklin JK, Naftel DC, Pagani FD, Kormos RL, Stevenson LW, Blume ED, Myers SL, Miller MA, Baldwin JT, Young JB. Seventh INTERMACS annual report: 15,000 patients and counting. J Heart Lung Transplant. 2015

6. Lalonde SD, Alba AC, Rigobon A, Ross HJ, Delgado DH, Billia F, McDonald M, Cusimano RJ, Yau TM, Rao V. Clinical differences between continuous flow ventricular assist devices: a comparison between HeartMate II and HeartWare HVAD. Journal of cardiac surgery. 2013; 28:60410. [PubMed: 23844652]

7. Kirklin JK, Naftel DC, Kormos RL, Pagani FD, Myers SL, Stevenson LW, Acker MA, Goldstein DL, Silvestry SC, Milano CA, Timothy Baldwin J, Pinney S, Eduardo Rame J, Miller MA. Interagency Registry for Mechanically Assisted Circulatory Support (INTERMACS) analysis of pump thrombosis in the HeartMate II left ventricular assist device. J Heart Lung Transplant. 2014; 33:12-22. [PubMed: 24418730]

8. Almond CS, Morales DL, Blackstone EH, Turrentine MW, Imamura M, Massicotte MP, Jordan LC, Devaney EJ, Ravishankar C, Kanter KR, Holman W, Kroslowitz R, Tjossem C, Thuita L, Cohen GA, Buchholz H, St Louis JD, Nguyen K, Niebler RA, Walters HL 3rd, Reemtsen B, Wearden PD, Reinhartz O, Guleserian KJ, Mitchell MB, Bleiweis MS, Canter CE, Humpl T. Berlin Heart EXCOR pediatric ventricular assist device for bridge to heart transplantation in US children. Circulation. 2013; 127:1702-11. [PubMed: 23538380]

9. Fraser CD, Jaquiss RDB, Rosenthal DN, Humpl T, Canter CE, Blackstone EH, Naftel DC, Ichord RN, Bomgaars L, Tweddell JS, Massicotte MP, Turrentine MW, Cohen GA, Devaney EJ, Pearce FB, Carberry KE, Kroslowitz R, Almond CS. Prospective Trial of a Pediatric Ventricular Assist Device. N Engl J Med. 2012; 367:532-541. [PubMed: 22873533]

10. Rosenthal DN, Almond CS, Jacquiss RD, Peyton CE, Auerbach SR, Morales DL, Epstein DJ, Cantor RS, Kormos RL, Naftel DC, Butts RJ, Ghanayem NS, Kirklin JK, Blume ED. (258) Adverse Events in Children Implanted With Ventricular Assist Devices in the US: Data From the Pediatric Interagency Registry for Mechanical Circulatory Support (Pedimacs). The Journal of Heart and Lung Transplantation. 2015; 34:S101-S102.

11. Fragasso T, Ricci Z, Grutter G, Albanese S, Varano C, Amodeo A, Cogo P. Incidence of healthcare-associated infections in a pediatric population with an extracorporeal ventricular assist device. Artificial organs. 2011; 35:1110-4. [PubMed: 22097984]

12. Cabrera AG, Khan MS, Morales DL, Chen DW, Moffett BS, Price JF, Dreyer WJ, Denfield SW, Jeewa A, Fraser CD Jr, Vallejo JG. Infectious complications and outcomes in children supported with left ventricular assist devices. J Heart Lung Transplant. 2013; 32:518-24. [PubMed: 23489988]

13. Blume ED, Rosenthal DN, Rossano JW, Baldwin JT, Eghtesady P, Morales DL, Cantor RS, Conway J, Lorts A, Almond CS, Naftel DC, Kirklin JK, Pedi MI. Outcomes of children implanted with ventricular assist devices in the United States: First analysis of the Pediatric Interagency Registry for Mechanical Circulatory Support (Pedimacs). J Heart Lung Transplant. 2016

14. Rosenthal DN, Almond CS, Jaquiss RD, Peyton CE, Auerbach SR, Morales DR, Epstein DJ, Cantor RS, Kormos RL, Naftel DC, Butts RJ, Ghanayem NS, Kirklin JK, Blume ED. Adverse events in children implanted with ventricular assist devices in the United States: Data from the Pediatric Interagency Registry for Mechanical Circulatory Support (Pedimacs). J Heart Lung Transplant. 2016; 35:569-77. [PubMed: 27197775]

15. Barach, P., Jacobs, J., Lipshultz, SE., Laussen, P. Pediatric and Congenital Cardiac Care. London: Springer-Verlag; 2015.

16. Ishino K, Loebe M, Uhlemann F, Weng Y, Hennig E, Hetzer R. Circulatory support with paracorporeal pneumatic ventricular assist device (VAD) in infants and children. Eur J Cardiothorac Surg. 1997; 11:965-72. [PubMed: 9196316]

17. Blume ED, Rosenthal DN, Rossano JW, Baldwin JT, Eghtesady P, Morales DL, Cantor RS, Conway J, Lorts A, Almond CS, Naftel DC, Kirklin JK, Pedi MI. Outcomes of children implanted with ventricular assist devices in the United States: First analysis of the Pediatric Interagency 
Registry for Mechanical Circulatory Support (Pedimacs). J Heart Lung Transplant. 2016; 35:57884. [PubMed: 27009673]

18. Rossano JW, Lorts A, VanderPluym CJ, Jeewa A, Guleserian KJ, Bleiweis MS, Reinhartz O, Blume ED, Rosenthal DN, Naftel DC, Cantor RS, Kirklin JK. Outcomes of pediatric patients supported with continuous-flow ventricular assist devices: A report from the Pediatric Interagency Registry for Mechanical Circulatory Support (Pedimacs). J Heart Lung Transplant. 2016; 35:58590. [PubMed: 27056612]

19. Miller JR, Epstein DJ, Henn MC, Guthrie T, Schuessler RB, Simpson KE, Canter CE, Eghtesady P, Boston US. Early Biventricular Assist Device Use in Children: A Single-Center Review of 31 Patients. ASAIO journal. 2015; 61:688-94. [PubMed: 26186261]

20. Rossano JW, Lorts A, VanderPluym CJ, Jeewa A, Guleserian KJ, Bleiweis MS, Reinhartz O, Blume ED, Rosenthal DN, Naftel DC, Cantor RS, Kirklin JK. Outcomes of pediatric patients supported with continuous-flow ventricular assist devices: A report from the Pediatric Interagency Registry for Mechanical Circulatory Support (Pedimacs). The Journal of Heart and Lung Transplantation. 2016; 35:585-590. [PubMed: 27056612]

21. Stein ML, Dao DT, Doan LN, Reinhartz O, Maeda K, Hollander SA, Yeh J, Kaufman BD, Almond CS, Rosenthal DN. Ventricular assist devices in a contemporary pediatric cohort: Morbidity, functional recovery, and survival. J Heart Lung Transplant. 2016; 35:92-8. [PubMed: 26210751]

22. Goldstein DJ, Naftel D, Holman W, Bellumkonda L, Pamboukian SV, Pagani FD, Kirklin J. Continuous-flow devices and percutaneous site infections: clinical outcomes. The Journal of heart and lung transplantation : the official publication of the International Society for Heart Transplantation. 2012; 31:1151-7.

23. Almond CS, Morales DL, Blackstone EH, Turrentine MW, Imamura M, Massicotte MP, Jordan LC, Devaney EJ, Ravishankar C, Kanter KR, Holman W, Kroslowitz R, Tjossem C, Thuita L, Cohen GA, Buchholz H, St Louis JD, Nguyen K, Niebler RA, Walters HL, Reemtsen B, Wearden PD, Reinhartz O, Guleserian KJ, Mitchell MB, Bleiweis MS, Canter CE, Humpl T. Berlin Heart EXCOR Pediatric Ventricular Assist Device for Bridge to Heart Transplantation in US Children. Circulation. 2013; 127:1702-1711. [PubMed: 23538380] 

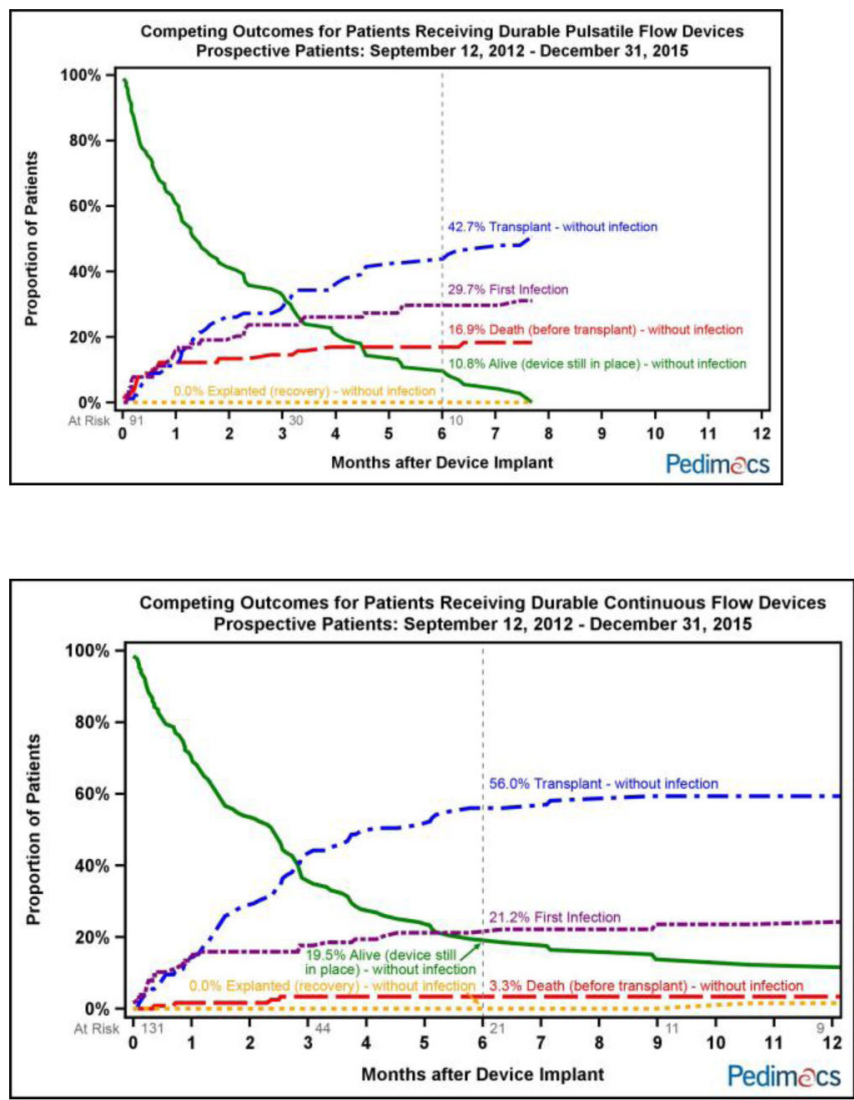

Figure 1.

Competing outcomes analysis with first infection as an outcome, separated by device type (pulsatile flow, 1A, and continuous flow, 1B). Outcomes include alive on device without infection, death before transplant without infection, transplanted without infection, explanted without infection, and first infection. 

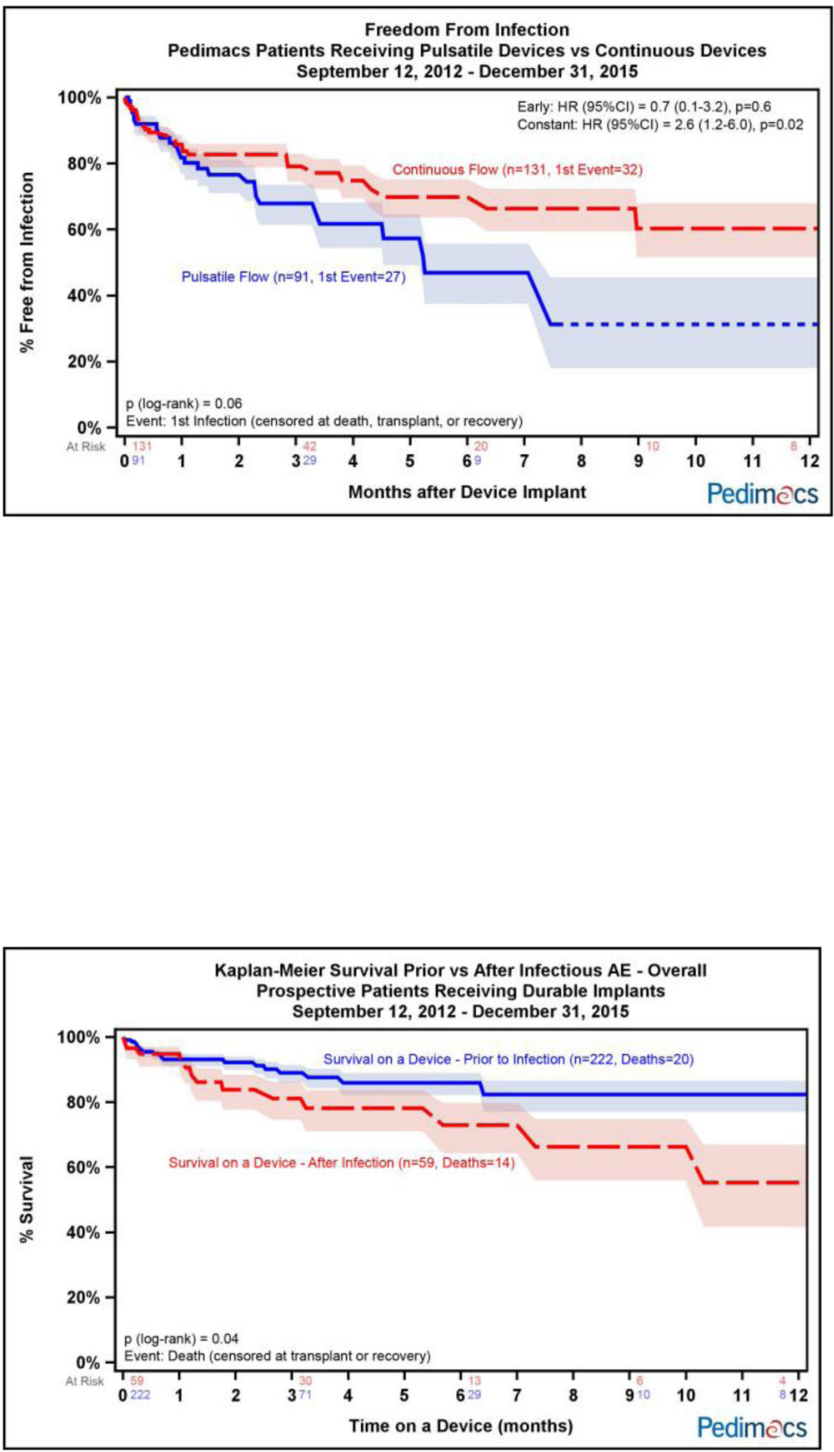

Figure 2.

Kaplan-Meier analysis showing time to first infectious adverse event of the entire cohort stratified by device type. 


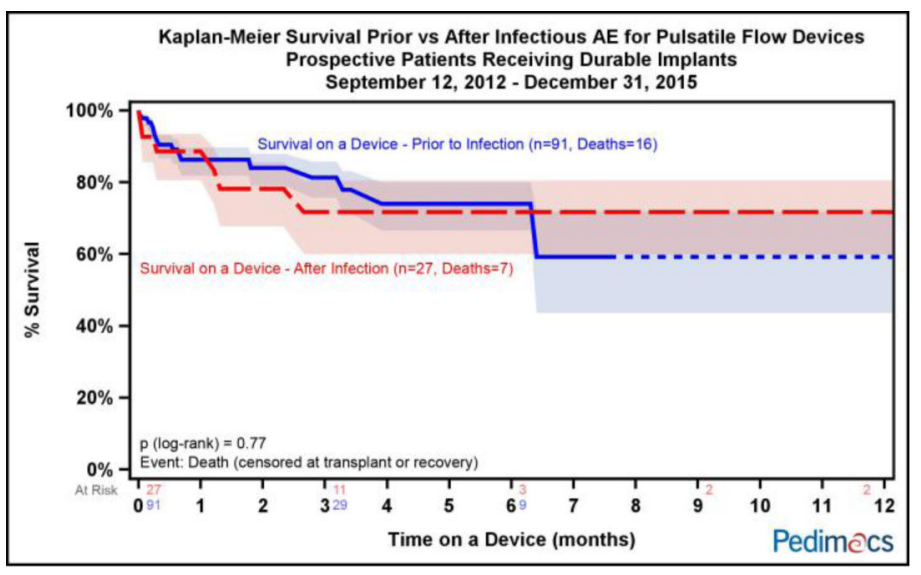

Kaplan-Meier Survival Prior vs After Infectious AE for Continuous Flow Devices Prospective Patients Receiving Durable Implants

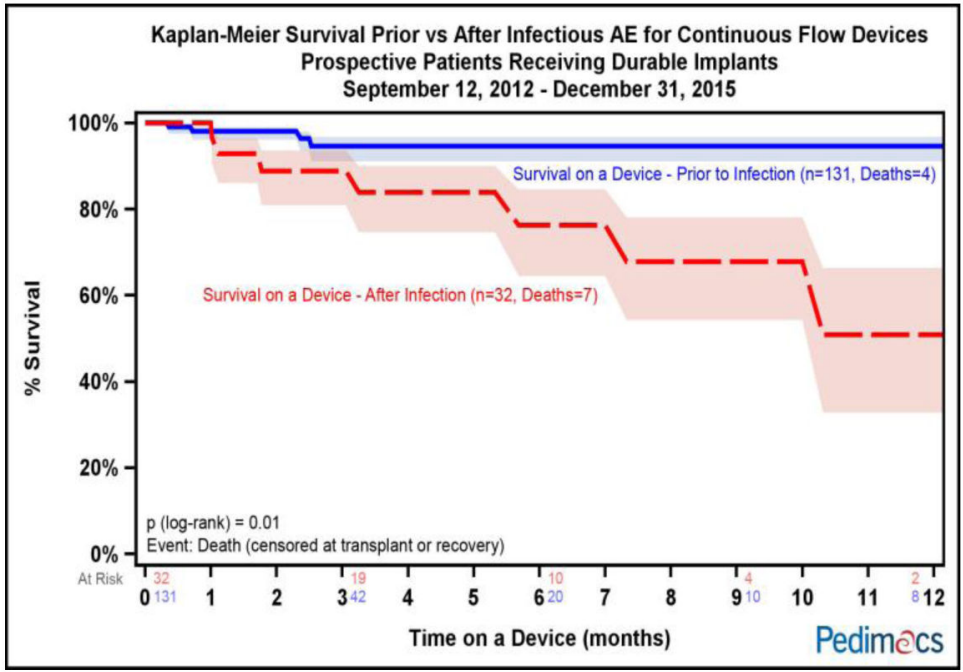

Figure 3.

Kaplan-Meier analysis utilizing a modulated renewal process comparing survival following a first infectious AE to survival in those without an infectious $\mathrm{AE}$ in all patients(5A), patients on PF devices (5B), and patients on CF devices (5C). 


\section{Table 1}

Patient Characteristics Prior to Implantation

\begin{tabular}{|c|c|c|c|}
\hline Baseline Characteristics & Pulsatile Flow, n=91 & Continuous Flow, $\mathbf{n}=131$ & p-value \\
\hline $\operatorname{Age}(\mathrm{y}) \pm$ std. dev. & $3.7 \pm 4.0$ & $14.2 \pm 3.5$ & $<.0001$ \\
\hline Female, $\mathrm{n}(\%)$ & $43(47.3)$ & $46(35.1)$ & 0.07 \\
\hline Cardiac Diagnosis, $\mathrm{n}(\%)$ & & & 0.03 \\
\hline 1. Congenital Heart Disease & $23(25.3)$ & $15(11.6)$ & \\
\hline 2. Dilated Myopathy & $55(60.4)$ & $105(81.4)$ & \\
\hline 3. Hypertrophic Cardiomyopathy & & $2(1.6)$ & \\
\hline 4. Restrictive Cardiomyopathy & $7(7.7)$ & $4(3.1)$ & \\
\hline 5. Post-Transplant/Graft Dysfunction & $4(4.4)$ & $2(1.6)$ & \\
\hline 6. Coronary Artery Disease & $1(1.1)$ & & \\
\hline 7. Unknown & $1(1.1)$ & $1(0.8)$ & \\
\hline 8. Cancer & & $1(0.8)$ & \\
\hline 9. Valvular Heart Disease & & $1(0.8)$ & \\
\hline Race, $\mathrm{n}(\%)$ & & & 0.56 \\
\hline African American & $18(19.8)$ & $31(23.7)$ & \\
\hline Other & $13(14.3)$ & $23(17.6)$ & \\
\hline White & $60(65.9)$ & $77(58.8)$ & \\
\hline Body Surface Area \pm std. dev. & $0.6 \pm 0.4$ & $1.6 \pm 0.4$ & $<.0001$ \\
\hline Previous ECMO, n(\%) & $22(24.2 \%)$ & $9(6.9 \%)$ & 0.0003 \\
\hline Previous Cardiac Surgery, n(\%) & $48(52.7)$ & $34(26)$ & $<.0001$ \\
\hline Brain Natriuretic Peptide $(\mathrm{pg} / \mathrm{mL}) \pm$ std. dev. & $2816.1 \pm 1952.8^{*}$ & $1586.2 \pm 1395.8^{*}$ & 0.0003 \\
\hline Pro Brain Natriuretic Peptide $(\mathrm{pg} / \mathrm{mL}) \pm$ std. dev. & $17992 \pm 15320 *$ & $10160 \pm 9926.3^{*}$ & 0.02 \\
\hline White Blood Cell Count $(x 103 / \mu \mathrm{L}) \pm$ std. dev. & $91,12.2 \pm 7.2$ & $131,9.6 \pm 3.7$ & 0.0007 \\
\hline Lymphocyte Count $(\%) \pm$ std. dev. & $24.9 \pm 15.6^{*}$ & $20.6+/-11.9^{*}$ & 0.04 \\
\hline eGFR $\mathrm{mL} / \mathrm{min} / 1.73 \mathrm{~m}^{2} \pm$ std. dev. & $83.6 \pm 40.6$ & $83.7 \pm 43.2$ & 0.98 \\
\hline Total Billirubin $(\mathrm{mg} / \mathrm{dL}) \pm$ std. dev. & $1.4 \pm 1.5^{*}$ & $1.6 \pm 2.3^{*}$ & 0.64 \\
\hline Malnutrition/cachexia & $3(3.3)$ & $4(3.1)$ & 1.00 \\
\hline Pulmonary hypertension, $\mathrm{n}(\%)$ & $3(3.3)$ & $15(11.5)$ & 0.03 \\
\hline
\end{tabular}

J Heart Lung Transplant. Author manuscript; available in PMC 2019 January 01. 
Table 2

Implant Characteristics Comparing Pulsatile and Continuous Flow Devices

\begin{tabular}{llll}
\hline Implant Characteristics & Pulsatile Flow (n=91) & Continuous Flow (n=131) & p-value \\
\hline Patient Profile & & & 0.01 \\
1. Critical Cardiogenic Shock & $30(34.9)$ & $21(16.5)$ & \\
2. Progressive Decline & $47(54.7)$ & $82(64.6)$ & \\
3. Stable but Inotrope Dependent & $6(7.0)$ & $19(15.0)$ & \\
4-7. Resting Symptoms or Less Sick & $3(3.5)$ & $5(3.9)$ & 0.003 \\
Pre-Implant Device Strategy & & & \\
1. Bridge to Transplant - Listed & $70(76.9)$ & $69(52.7)$ & \\
2. Bridge to Candidacy & $18(19.8)$ & $55(42.0)$ & \\
3. Destination Therapy & $2(2.2)$ & $5(3.8)$ & $<.0001$ \\
4. Bridge to Recovery & & $2(1.5)$ & \\
5. Other & $1(1.1)$ & & \\
Pre-Implant Device Type & & $122(93.1)$ & \\
1. LVAD & $65(71.4)$ & $2(1.5)$ & \\
2. RVAD & $2(2.2)$ & $7(5.3)$ & \\
3. BiVAD & $24(26.4)$ & &
\end{tabular}




\section{을 \\ 골}

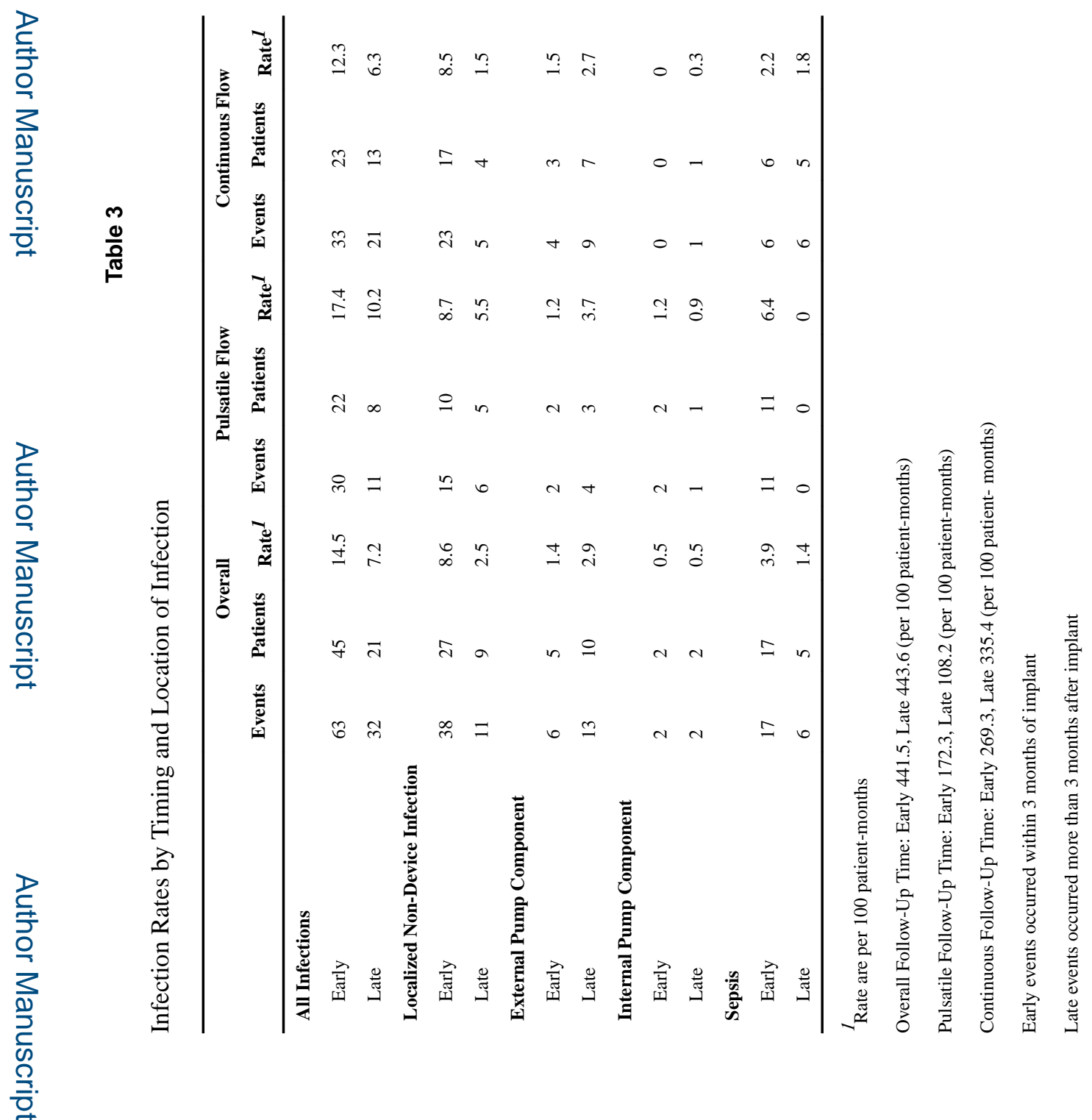

J Heart Lung Transplant. Author manuscript; available in PMC 2019 January 01. 


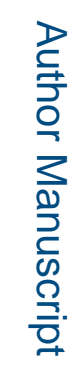

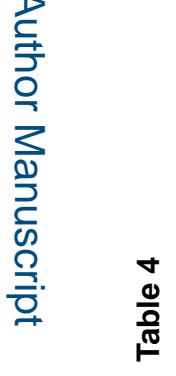

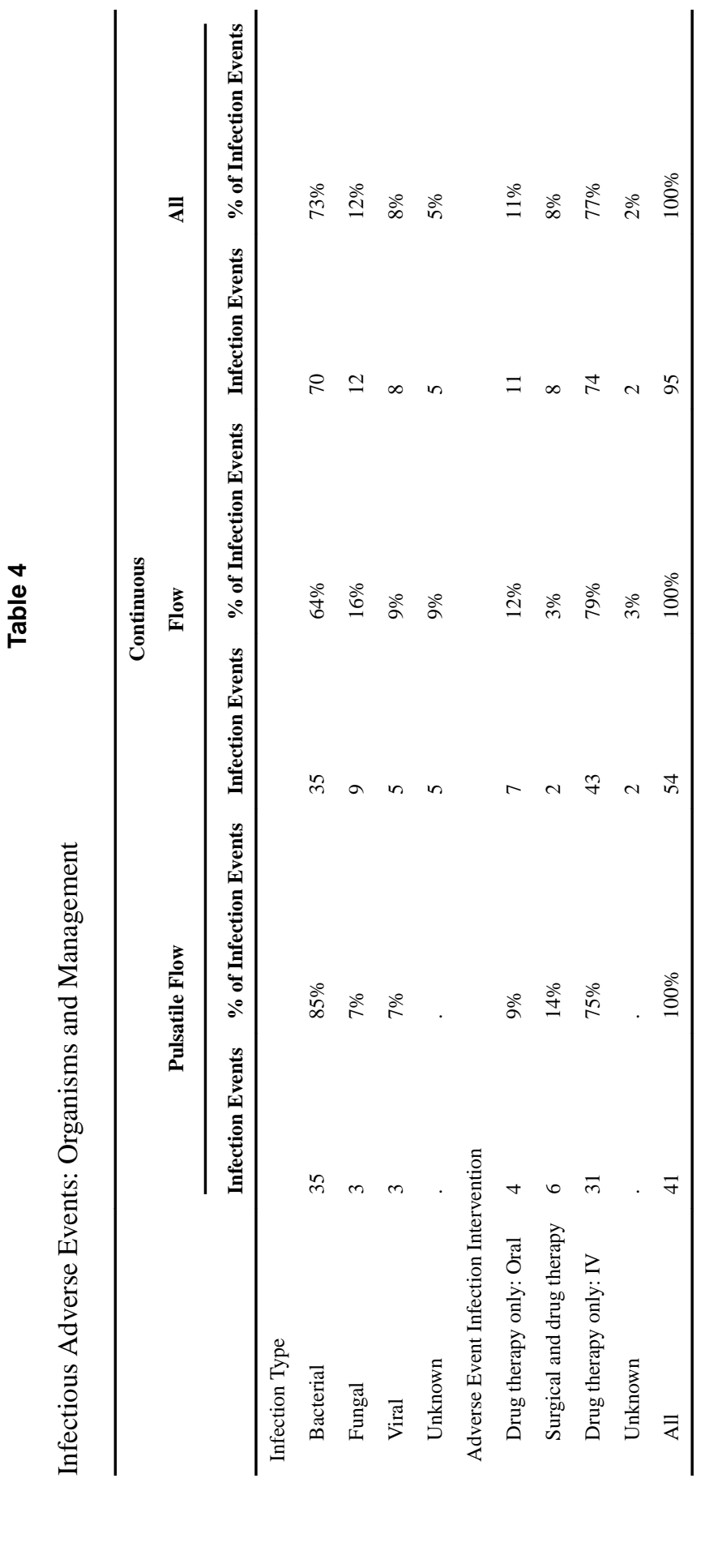

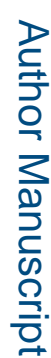

J Heart Lung Transplant. Author manuscript; available in PMC 2019 January 01. 
Table 5

Association of Infectious Adverse Events with Other Major Adverse Events

\begin{tabular}{llccc}
\hline & \multicolumn{2}{c}{ Early Phase $^{\boldsymbol{a}}$} & \multicolumn{2}{c}{ Constant Phase $^{\boldsymbol{b}}$} \\
& HR (95\% CI) & p-value & HR (95\% CI) & p-value \\
\hline Flow Type - PF vs CF & $0.9(0.3-3.1)$ & 0.9 & $1.5(0.8-2.9)$ & 0.2 \\
History of Prior Infection & $1.7(0.1-25.8)$ & 0.7 & $1.9(1.0-3.4)$ & 0.04 \\
History of Prior Non-Infection Major AE & $1.3(0.2-9.1)$ & 0.8 & $1.9(1.0-3.8)$ & 0.05 \\
\hline
\end{tabular}

PF: Pulsatile Flow Device; CF: Continuous Flow Device; AE: Adverse Event

Major Bleeding, Neurological Dysfunction, or Device Malfunction Event

a approximately 20 events are accounted for in the early phase

$b$ approximately 74 events are accounted for in the constant phase 